\title{
Distribution and abundance of the Amami rabbit Pentalagus furnessi in the Amami and Tokuno Islands, Japan
}

\author{
Ken Sugimura, Shigeho Sato, Fumio Yamada, Shintaro Abe, Hirofumi Hirakawa and Yukari Handa
}

\begin{abstract}
The Amami rabbit Pentalagus furnessi is a rare forest-dwelling form endemic to the Amami and Tokuno Islands in Japan. In order to estimate the distribution and abundance of the Amami rabbit we counted their faecal pellets along forest roads and streams as well as within the forests on Amami and Tokuno Islands during January 1993-March 1995. The number of pellets $/ \mathrm{km}$ along a stream gave a practical index for measuring relative abundance. The rabbit was estimated to be distributed over about $370 \mathrm{sq} \mathrm{km}$ on Amami Island and $33 \mathrm{sq} \mathrm{km}$ on Tokuno Island. There was a large variance in faecal abundance among the survey routes. Some populations were completely isolated and thought
\end{abstract}

\section{Introduction}

The Nansei Archipelago in the south-western part of Japan has many endemic species. In terms of primitive morphological characteristics (Chapman \& Flux, 1990) and limited range of distribution, the Amami rabbit Pentalagus furnessi (Plate 1) is one of the most remarkable of these species. It is found only on Amami and Tokuno Islands and has been designated as 'a special natural monument' by the Japan National Agency of Cultural Affairs. Therefore, it has been protected from hunting. It is found exclusively in forested areas (Plate 2) where extensive clear-cut forestry has been conducted primarily for pulpwood production since the 1950s (Sugimura, 1988). However, there are no survey

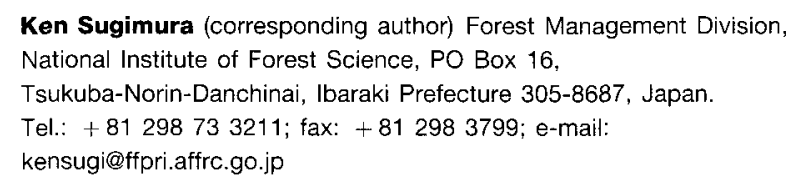

Shigeho Sato National Institute of Forest Science, Shikoku Research Center, 915 Tei, Asakura, Kochi 780-8064, Japan.

Fumio Yamada Forest Animals Division, National Institute of Forest Science, PO Box 16, Tsukuba-Norin-Danchinai, Ibaraki Prefecture 305-8687, Japan.

Shintaro Abe and Yukari Handa Amami Mammalogical Society, Japan.

Hirofumi Hirakawa National Institute of Forest Science, Hokkaido Research Center, Japan.

Revised manuscript accepted for publication 3 March 2000 to be very small. The size of a local population was positively correlated with those of neighbouring populations and the amount of mature forest relative to other seral stages. We compared the results of this survey with those of previous surveys to find that the total population of this species appears to be declining. Some conservation measures are proposed for forest habitat management, designed to avert the decline of the Amami rabbit and to ensure its preservation.

Keywords Abundance index, endangered species, forest management, population trend, wildlife conservation.

data to illuminate the relationship between the impact of this rather drastic habitat change and the rabbit's population. It is essential to establish an effective census method that can be used to determine what actions may be necessary to protect the species or any local populations from extinction.

Although various census techniques have been applied to lagomorph populations (Seber, 1982), the use of pellet counts is often the only viable approach. This method has been used frequently in the study of the Amami rabbit because direct observation (e.g. horseback counts; Wywialowski \& Stoddart, 1988; Duthie et al., 1989; Velazquez, 1994) is not practical because of the dense vegetation cover, which restricts visibility. Only 0.06 individuals $/ \mathrm{km}$ were observed during a spotlight census, even at sites that were thought to support high densities (Yamada \& Sugimura, unpublished data). Trapping a sufficient number of rabbits to estimate population size has not yet been successful, and track counts are not appropriate because there is no snow in winter.

The first Amami Island rabbit-pellet count was conducted in 1976 (Anon., 1977). Pellets were numerous on all the forest roads visited on Amami Island. The rabbit's distribution on the island was also assessed by way of a questionnaire and interviews with local people.

During two periods, $1985-86$ and 1989-90, pellets were counted along forest roads to investigate habitat preference in relation to the seral stages following clearcutting (Sugimura, 1988, 1993). These studies were 


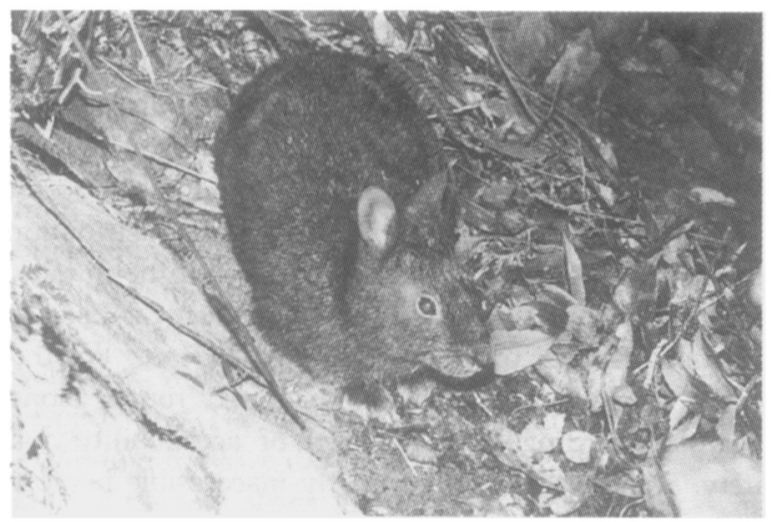

Plate 1 An Amami rabbit (Yoshitaka Takatsuki).

conducted in the central part of Amami Island, where progressive clear-cutting had created various stages of succession. They indicated that the rabbit used most heavily 10-40-year-old secondary forests. Yet, in spite of continuous cutting and an increase in the area of young forests, these studies suggested a decline in both abundance and distribution of the rabbit between the two periods. The major problem of these studies in assessing the population trend is that the areas surveyed were only a small portion of the inferred distribution range on Amami Island. Populations on Tokuno Island were not studied. In addition, forestry proponents felt that the decline was only along roads and not within the forests (Y. Miyauchi, former director of the Amami Regional Forest Office, pers. comm.). There are, however, no survey data to substantiate this claim.

The aims of the present study were to: (1) examine the feasibility of using faecal abundance along a survey route as an index of distribution and abundance of the rabbit, comparing the results of the route surveys with those of area surveys within forest; (2) delimit the probable distribution range and degree of isolation of local populations; (3) examine the relative abundance of local populations in relation to forest logging; and (4) propose effective strategies for the rabbit's conservation.

\section{Materials and methods}

The Amami rabbit is found on Amami Island $(820 \mathrm{sq} \mathrm{km})$ and Tokuno Island $(248 \mathrm{sq} \mathrm{km})$ in the Nansei Archipelago (Fig. 1). Both islands are located in the southern part of the temperate region (mean annual temperature of $21^{\circ} \mathrm{C}$ ). Amami Island is mountainous with a forest cover of 85 per cent, while Tokuno Island has a relatively large area of low-altitude cleared farmland; forests cover 44 per cent of the island. Precipitation is abundant throughout the year $(2871 \mathrm{~mm}$; the average of 30 years) without any distinguishable dry season. The highest peaks are $694 \mathrm{~m}$ on Amami Island and $645 \mathrm{~m}$ on Tokuno Island (Kagoshima-ken Amami Regional Office, 1999).

Signs of Amami rabbit have been found in forests (mature and regrowth), and cut-over areas dominated by perennial grasses (Sugimura, 1987). We included all these areas in our survey, except small patches that were completely isolated by paved roads, agricultural fields and/or residential areas. At present, broad-leafed evergreen forests (particularly of Castanopsis sieboldii and Schima wallichii) dominate the islands. Perennial grasses Miscanthus sinensis and ferns Dicranopteris pedata predominate in cut-over areas (Shimizu et al., 1988). Some areas of Ryukyu pine Pinus luchuensis and Japanese cedar Cryptomeria japonica are present. These were planted using government subsidies, but most plantations were abandoned because they were not commercially profitable.

The route surveys on Amami Island were conducted in January, July and December 1993, and FebruaryMarch, July-August and December 1994. In total, we spent 292 person-days: 7.6 times more person-days in winter than in summer ( 1 day is $c .8$ consecutive $h$ ). The
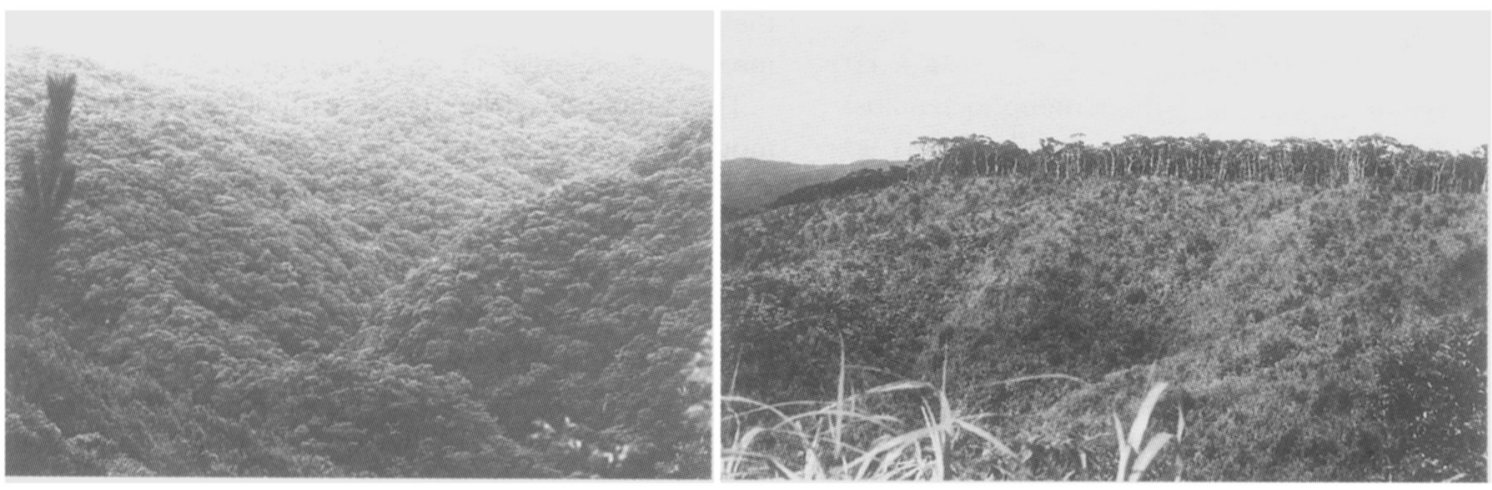

Plate 2 Typical rabbit habitat (left: mature forest, right: cut-over area) (Ken Sugimura). 


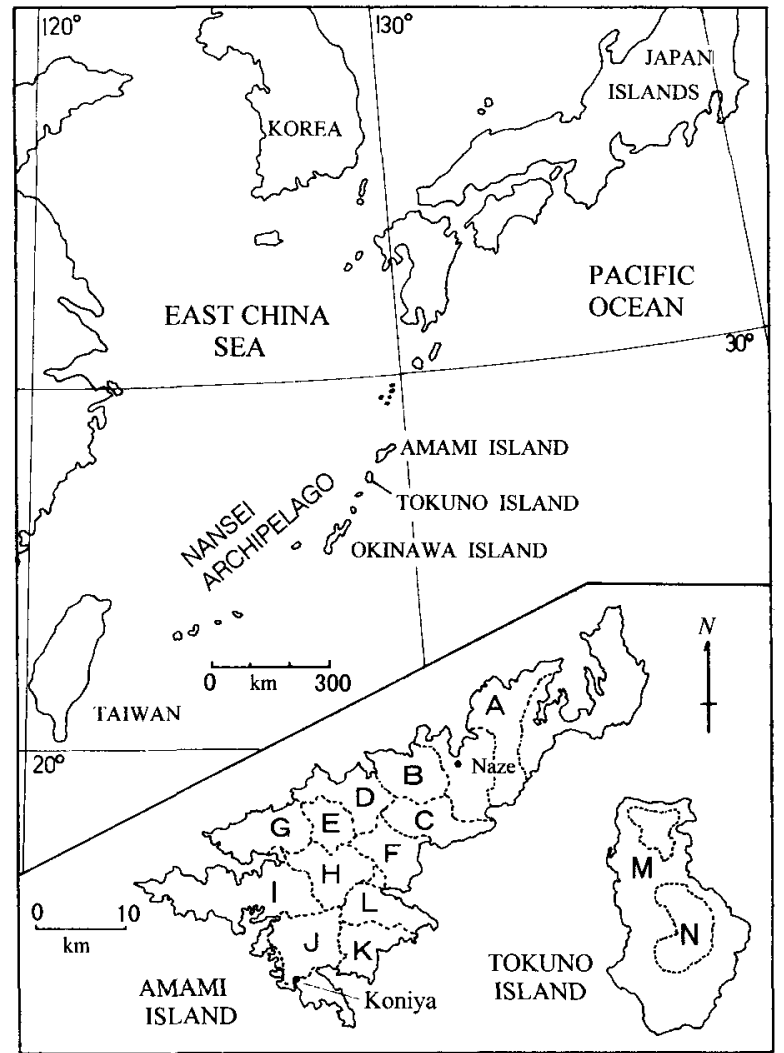

Fig. 1 The location and divisions of the Amami rabbit survey areas in south-western Japan.

Table 1 The distance of route surveys and the areas covered by interior forest surveys for faecal-pellet counts of the Amami rabbit, January 1993-March 1995

\begin{tabular}{lccl}
\hline Region & Road $(\mathrm{km})$ & Stream $(\mathrm{km})$ & Forest (ha) \\
\hline A & 66.2 & 12.8 & \\
B & 20.4 & 10.9 & 0.5 \\
C & 42.5 & 17.3 & 2.3 \\
D & 41.2 & 15.6 & \\
E & 36.5 & 29.4 & 0.8 \\
F & 42.7 & 17.5 & 2.8 \\
G & 36.0 & 16.5 & \\
H & 43.4 & 15.6 & \\
I & 19.5 & 14.2 & 1.7 \\
J & 44.2 & 23.2 & \\
K & 41.2 & 7.2 & \\
L & 35.6 & 13.1 & 2.6 \\
M & 24.0 & 10.1 & \\
N & 16.6 & 18.1 & 10.7 \\
Total & 510.0 & 221.5 & \\
\hline
\end{tabular}

surveys on Tokuno Island were conducted in March 1995 and took 55 person-days. We searched for pellets while walking along $92 \mathrm{~km}$ of forest roads and $221.5 \mathrm{~km}$ of streams. We also drove along $417 \mathrm{~km}$ of roads at about $10 \mathrm{~km} / \mathrm{h}$, with two people looking to either side of the car and one looking ahead.

We divided the whole range of rabbit distribution into 14 regions, $\mathrm{A}-\mathrm{N}$ (average $4331 \mathrm{ha}$ ) (Fig. 1), which were separated by highways, rivers and major forest roads. The survey routes covered the entire distribution range (Table 1). When pellets were found, the number and location were recorded. A pedometer was used to measure distance when we searched on foot. We traversed every forest road, and selected routes along streams according to their level of accessibility and safety. Some streams were nearly inaccessible because of waterfalls and/or dense herbaceous cover on steep slopes created after clear-cutting. A poisonous species of snake, the habu Trimeresurus flavoviridis, is generally active from mid-March to late November, so we conducted stream surveys in the winter months (from December to early March) and road surveys mainly in July and August in order to avoid encounters with the snake.

We counted pellets inside the forest in February and December 1994 on Amami Island and in March 1995 on Tokuno Island, in order to compare their number and distribution with those along streams and roads passing through the forests. This search technique used a line of 7-10 people separated by $1-1.5 \mathrm{~m}$ depending on the level of visibility. Such surveys were conducted at eight sites in six regions (Table 1) spending a half or full day at each site; the areas covered ranged from 0.6 to $1.7 \mathrm{ha}$. The forest floor of four other localities covering $0.1-0.4$ ha was also searched by individual workers along transects c. $1.5 \mathrm{~m}$ wide in December 1993 on Amami Island, spending half a day for each in regions $B, C$ and $F$.

Some forests were selectively logged before World War II. We defined both these and uncut forests as mature forests. We examined forest records at the local municipal office, and marked the locations and size of mature forests on topographical maps. We also used aerial photographs to locate cut-over areas and marked their boundaries on topographical maps in order to measure their areas using a planimeter.

The 14 regions (Fig. 1) were divided further using mountain ridges into 286 subregions (average 212 ha) so that the regional variance in the rabbit's abundance could be analysed. The area of the rabbit's distribution range was estimated based on the presence of pellets in each subregion. There were more pellets along the forest roads that were closest to streams than along those further from the streams (Sugimura, 1993). We concluded, therefore, that the rabbits used the areas near streams quite heavily and that it was reasonable to use a catchment area to estimate the local rabbit abundance. 


\section{Results}

Comparison of faecal distribution along the routes

Rabbit faeces were found in piles comprising varying numbers of pellets ( $28.7 \pm$ SD 22.1). These latrines were often found close together.

Within the forests we found an average of 0.11 pellets/sq $\mathrm{m}$ over 12 sites. Averages of 0.47 and 0.97 pellets $/ \mathrm{m}$ were found along the roads and streams, respectively. The area of forests and cut-over areas, including those we did not survey, greatly exceeded the area of narrow strips of road and streamsides, which were $c .1-7 \mathrm{~m}$ wide. Multiplying the pellet density by the area, it is apparent that the total number of pellets present within the forests and cut-over areas was far greater than that along roads and streams at all localities. Therefore, for an index to be an appropriate indicator of rabbit abundance, it is essential that it has a good correlation with the pellet density within the forest. Figure 2 indicates that the variance from the regression line was smaller for the stream data than the road data. Thus, we decided that we would use
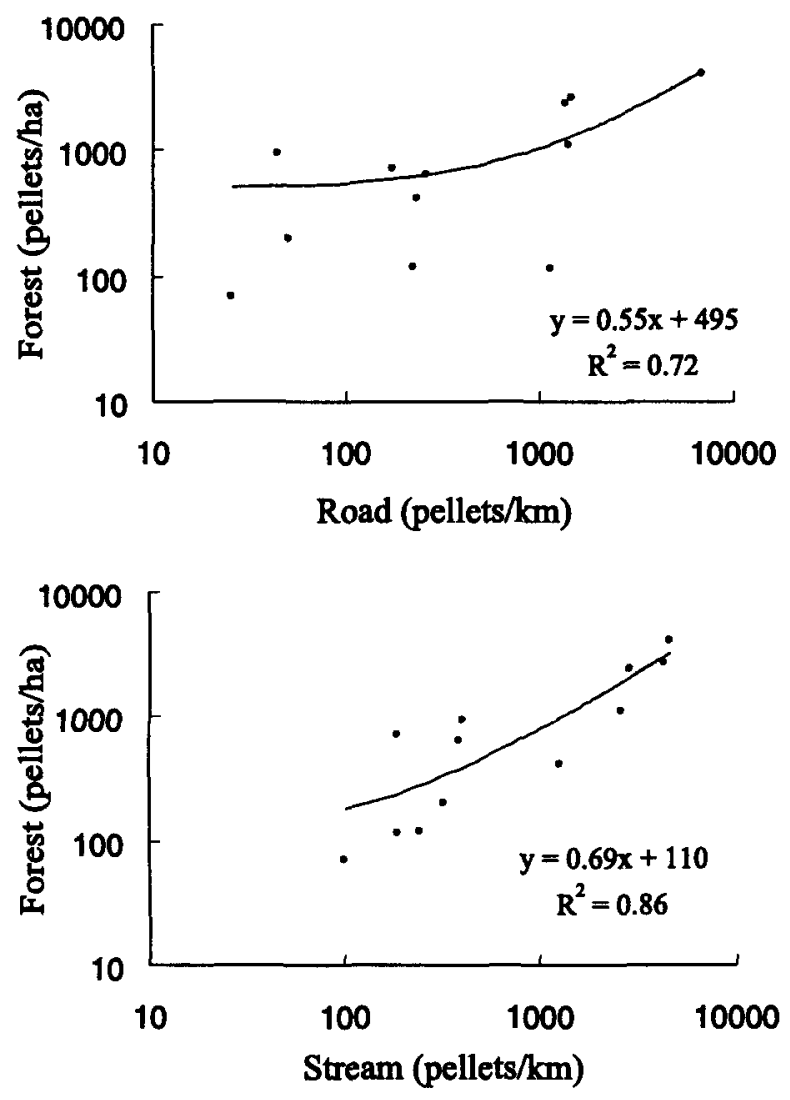

Fig. 2 The relationship between the number of rabbit faecal pellets within the forests and along roads (top) and streams (bottom). the total number of pellets $/ \mathrm{km}$ along streams as the primary index of rabbit abundance.

Another contrast between the roads and the streams was that pellets were found more often along streams than on roads. Pellets were found on 73 of the 118 road surveys (62 percent), compared with 88 of the 96 stream surveys (92 per cent). Of the 55 routes we searched for pellets along both roads and nearby streams, pellets were found along 91 percent of the streams but only on 40 per cent of the roads. Yet, the correlation between them was good. Using the following regression equation, we estimated the number of pellets along a stream from that on a road where pellets were counted along a road but not along a stream:

$y=1.84 x /\left(1+3.06 \times 10^{-4} x\right)\left(R^{2}=0.83\right)$,

where $y$ is the number of pellets along a stream and $x$ is the number on a road.

\section{Distribution and abundance}

We estimated the distribution range by summing the areas of the subregions where pellets were counted; a total of 37,028 ha on Amami and 3297 ha on Tokuno Island. Regions $\mathrm{A}, \mathrm{M}$ and $\mathrm{N}$ were completely isolated from all the other regions by agricultural fields and residential areas (Fig. 1), and the areas were small (Table 2). Regions $\mathrm{K}$ and $\mathrm{L}$ were also separated from the other regions by a vehicular road with relatively heavy traffic. Pellets were absent from the major peninsulas on Amami Island (in the eastern part of region A, the western part of region $I$, and the southern part of region J).

Figure 3 shows the pellet frequency in the subregions, and Table 2 shows the regional variance in abundance. These data indicate that pellet abundance had the following characteristics: (a) the numbers of pellets observed had a very large variance, possibly influenced by both sampling biases and environmental variables; (b) the variances within the same region were smaller than those among the 14 regions $(P<0.001$ $(H=40.4)$; Kruskal-Wallis test); and (c) the size of the isolated populations (i.e. A, M and N) was inferred to be small relative to most of the others, because their pellet frequencies were below the average and their ranges were small.

\section{Faecal abundance in relation to forestry}

Using a stepwise-forward regression, correlation of faecal pellet frequency in each subregion was analysed with the area of mature forests, the area of cut-over forests and faecal pellet frequency in the neighbouring subregions. Only faecal pellet frequency in the neigh- 
Table 2 The frequency of Amami rabbit faecal pellets found in 14 regions

\begin{tabular}{|c|c|c|c|}
\hline Region & Area* (ha) & $\begin{array}{l}\text { Average frequencyt } \\
\text { (pellets } / \mathrm{km} \text { ) }\end{array}$ & Range \\
\hline A & 2294 & 26 & $4.3-28$ \\
\hline B & 1601 & 250 & $6.7-230$ \\
\hline C & 2878 & 1100 & $110-6300$ \\
\hline $\mathrm{D}$ & 2721 & 230 & $3.2-2000$ \\
\hline E & 2613 & 870 & $3.5-3300$ \\
\hline F & 4535 & 600 & $18-2900$ \\
\hline G & 4160 & 830 & $180-2300$ \\
\hline $\mathrm{H}$ & 2940 & 740 & $110-1800$ \\
\hline 1 & 4250 & 490 & $35-1900$ \\
\hline J & 3403 & 980 & $50-3600$ \\
\hline K & 2757 & 1500 & $210-4900$ \\
\hline L & 2876 & 1300 & $250-2400$ \\
\hline$M$ & 1515 & 720 & $1.6-3000$ \\
\hline N & 1782 & 270 & $80-730$ \\
\hline Total & 40,325 & 800 & $1.6-6300$ \\
\hline
\end{tabular}

* The sum of the subregions where pellets were found.

t The area of a subregion is weighted in calculating the average.

bouring subregions had a significant correlation $(R=$ 0.34 ). We then divided the whole distribution range into 39 areas by amalgamating some subregions, and the following equation was obtained:

$\ln P=1.3 \ln N+0.0019 *(68-M) * M+0.057 L$

$+1.0\left(R^{2}=0.61\right)$

where $P$ is the number of pellets observed $/ \mathrm{km}, M$ is the percentage of mature forest, $L$ is the percentage of cut-over forest, and $N$ is the number of pellets observed $/ \mathrm{km}$ in the neighbouring regions weighted by the length of the region's borders.
This equation suggests that the rabbit's abundance is positively correlated with the percentage of mature forests, because it was generally below 34 percent (refer to the average and SD of $M$ in Table 3). Thus, in general, the larger the area of mature forests, the greater the rabbit's abundance. The equation also suggests that opening up a forest may contribute to an increase in the abundance of the Amami rabbit. However, cut-over forests varied from nearly bare ground immediately after clear-cutting to areas densely covered with perennial grasses that were potential food for the rabbit. This might have been a major factor in the low correlation of the cut-over areas with the abundance of faecal pellets (Table 3).

\section{Discussion}

\section{Abundance index}

In previous studies of the Amami rabbit, the number of pellets along a forest road $\left(N_{r}\right)$ was used as an index of the rabbit's distribution and abundance. However, the results of our study indicate that the number of pellets along a stream $\left(N_{\mathrm{s}}\right)$ gives a better index than that along a road. The reasons for this are: (a) there is a better correlation between $N_{s}$ and faecal density on forest floors than $N_{r}$; (b) pellets were found more frequently along streams than along roads, so the rabbit's range should be able to be estimated more reliably by $N_{s}$ than $N_{r}$; and (c) streams are distributed more evenly than roads throughout the estimated range, providing more effective survey routes. Road surveys are much less time-consuming than stream surveys, so $N_{r}$ could supplement $N_{s}$ (Equation 1).

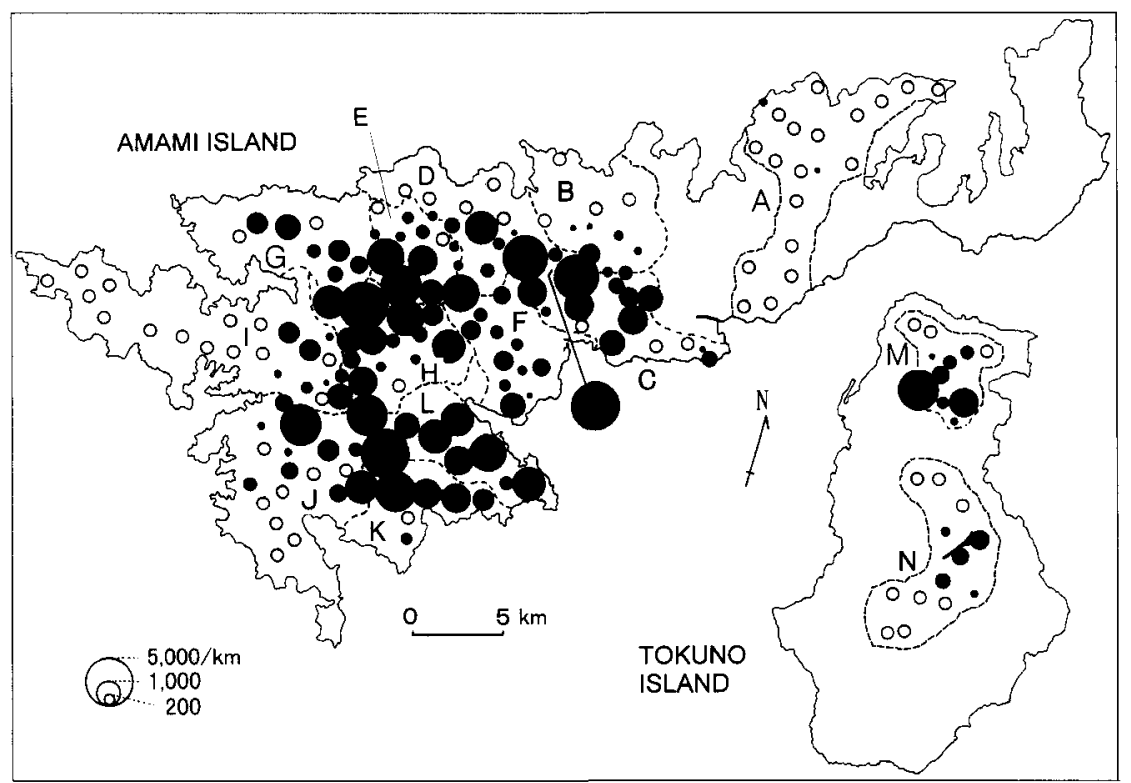

Fig. 3 The abundance of the Amami rabbit faecal pellets over the whole distribution area. Open circles indicate that no pellets were observed. The abundance at a location (pellets $\mathrm{km}$ ) is proportional to the area of the solid circles. 
Table 3 Summary of the multiple regression analysis of Amami rabbit faecal abundance

\begin{tabular}{lcrrl}
\hline & Mean \pm SD & Min-max & Partial correlation coefficient & $P$ value \\
\hline $\ln P$ & $5.8 \pm 1.9$ & $-1.1-7.9$ & & \\
$\ln N$ & $2.5 \pm 0.8$ & $-1.4-3.2$ & 0.68 & 0.00001 \\
$M$ & $17 \pm 17$ & $0-59$ & 0.44 & 0.0079 \\
$M^{2}$ & & & -0.36 & 0.031 \\
$L$ & $4.4 \pm 5.4$ & $0-22$ & 0.24 & 0.16 \\
\hline
\end{tabular}

$P$ : the number of pellets observed $/ \mathrm{km} ; M$ : the percentage of mature forest; $L:$ the percentage of cut-over; $N$ : the number of pellets in neighbouring regions weighted by the length of their borders.
Our study was conducted over a period of 2 years in some regions, but it is expected that the use of data from different years will not cause a serious problem. This is because the home range of an individual rabbit over a year is less than 5 ha (estimated by Yamada et al., 2000) and this area is much smaller than the size of our established subregions (average $212 \mathrm{ha}$ ). Therefore, the movement of rabbits between subregions would not affect the results of the surveys conducted over 2 years. In addition, Sugimura (1998) estimated that the latrines stayed on the survey routes for 26 days on average, before heavy rains flushed them away or dung beetles and fungi broke them down (Sugimura, 1987; Tsukamoto, 1989; Glockling \& Yamada, 1997).

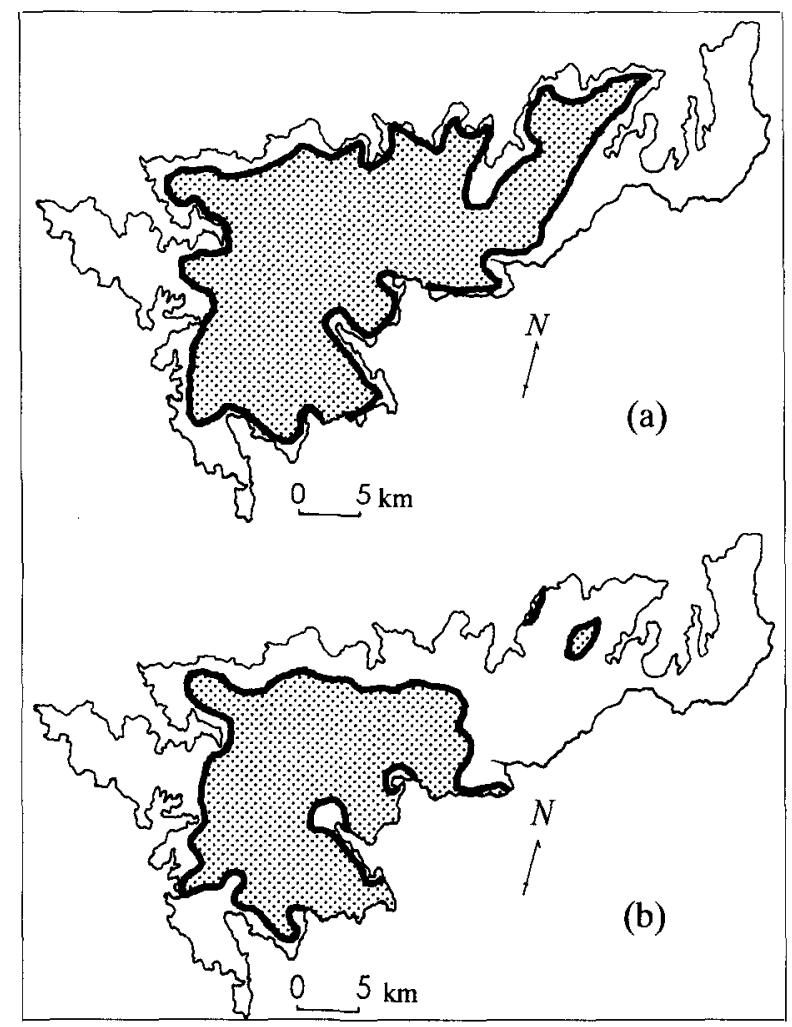

Fig. 4 Change in the estimated distribution range between (a) 1976 and (b) 1993-94 on Amami Island, (a) was taken from Anon. (1977).

\section{Population trend}

A comparison of the results of this study with those of previous studies indicates that the Amami rabbit's total population has declined over the last two decades. Numerous pellets were found on the roads throughout the distributional range of the rabbit on Amami Island (Anon., 1977). This study proposed 233 pellets $/ \mathrm{km} /$ day as an average on the three roads ( $1 \mathrm{~km}$ for each) visited daily in 1976. In a series of studies in the central part of Amami Island (regions B-F in Fig. 1), the proportion of road routes where no pellets were found increased markedly from the winter of 1985-86 (27 per cent) to the winter of 1990 (59 per cent). The average faecal abundance decreased from 47.2 pellets $/ \mathrm{km} /$ day in $1985-86$ to 13.3 pellets $/ \mathrm{km} /$ day in 1989-90 (Sugimura, 1987, 1993). In our study (1993-95), the average calculated from Table 2 was 640 pellets $/ \mathrm{km}$ for the same area and 800 pellets $/ \mathrm{km}$ for the whole range. Using Equation (1), this study's figures for stream routes can be converted to 390 and 500 pellets $/ \mathrm{km}$, respectively, for road routes. These are equivalent to 15 and 19 pellets $/ \mathrm{km} /$ day, respectively (the denominator for conversion was 26 according to Sugimura (1998)). Thus, a declining population trend is apparent when the figures before 1986 and those after 1989 are compared.

Anon. (1977) estimated the range based on a questionnaire survey, interviews and pellet searches on some forest roads. When the past range is compared with the faecal distribution in the present study (Fig. 4), it appears that the geographic range has shrunk in the west of region $A$, the northern part of regions $B$ and $D$, and the western parts of both regions $G$ and $I$. The western parts of regions $G$ and I are both on peninsulas. New vehicle roads were constructed between the two survey periods, and these might have blocked rabbit movements and induced their disappearance from those areas. The southern parts of regions $\mathrm{A}$ and $\mathrm{J}$ have also been separated from the range by one of the major vehicle roads. The disappearance of the rabbit from regions $B$ and $D$ may be because of the introduction of the mongoose as described below. The scale of range 
reduction is uncertain because the estimation method of the past range is different from that of the present study.

Mature forests make up about 10 per cent of the area on Amami Island (Sugimura, 1995) and cover no more than 30 per cent on Tokuno Island, according to forestry statistics (Ministry of Agriculture, Fishery and Forestry, 1991). Sugimura (1988) assigned the cause of population decline to extensive clear-cutting of mature forests. He found a larger number of faecal pellets in young secondary forests than in mature forests. Yet, more pellets were found in young secondary forests close to mature forests than in young secondary regrowth further from mature forests. In the present study, a positive correlation was obtained between faecal abundance and the area of mature forests when the subregions were aggregated together. These findings imply that a mixture of mature and young forests makes up a suitable habitat for the rabbit over the long term.

The Mexican volcano rabbit Romerolagus diazi is another important species in terms of lagomorph conservation (Chapman \& Flux, 1990). Fa et al. (1992) and Velazquez \& Heil (1996) indicated the importance of herbaceous cover in supporting higher population levels of the volcano rabbit. In contrast, mature forests could be important for the Amami rabbit because their acorn production is high in late autumn and could provide an important food source for the rabbits (Sugimura, 1987). Herbaceous cover in mature forests was generally poor (c. 20 per cent), except along streams and in valley bottoms where ferns were dominant (Miyawaki et al., 1974). Herbaceous cover is richer in young forests and cut-over areas, and Sugimura (1987) observed numerous feeding signs on perennial grasses Miscanthus sinensis and ferns Dicranopteris pedata. Kirino et al. (1984) indicated that the rabbits in captivity were fond of Miscanthus sinensis, which is dominant in cut-over areas and along roads in young forests, as well as acorns of Castanopsis sieboldii, which is the predominant species in mature forests (Shimizu et al., 1988). Furthermore, pellet abundance near mature forests was higher in winter than in summer (Sugimura, 1988). These observations suggest that the abundance of Amami rabbits in mature forests may be more related to the level of acorn production than herbaceous cover. However, the relationship between vegetation types and rabbit abundance as well as food habits must be studied in order to confirm the importance of mature forests.

\section{Conservation measures}

The present study indicates that, although the Amami rabbit may not yet be on the brink of extinction, certain urgent measures need to be taken if the species is to be conserved. The total rabbit population appears to be declining and some small isolated local populations may become extinct if the distribution range shrinks further. The size of the geographic range of the Amami rabbit estimated here is close to that of the volcano rabbit (280 sq km) (Hoth et al., 1987; Fa \& Bell, 1990). Both of these species retain primitive morphological characteristics among lagomorph species (Chapman \& Flux, 1990) and their distribution appears to have been shrinking (Velazquez, 1994). Conservation of the Amami rabbit may be regarded as urgent as is claimed for the volcano rabbit.

Our study suggests that such action should have two objectives. These are: (i) to save small local populations from extinction; and (ii) to maintain relatively high population levels in all other areas. Three measures would be effective to achieve both of these objectives: (a) restrict extensive logging of mature forests to maintain a widespread mosaic of cut-over and mature forests; (b) control predators (feral cats and dogs and introduced mongooses); and (c) cease forest road construction that may encourage further expansion of predators in forests.

A recent study (Yamada et al., 2000) indicates that the mongoose, introduced to Amami Island around 1979, has expanded its range from region B towards regions $E$ and $F$, and that 8 per cent of their droppings contained rabbit fur. Because the total mongoose population has increased rapidly and they prey on rabbits, they probably have contributed to lowering the rabbit's population in regions $B$ and $D$. Amami rabbits may have already been eliminated in region B (K. Fujimoto, official at the Amami Regional Forest Office, pers. comm.). Sugimura (1993) found rabbit fur in 8 of 11 dog faeces. Predation by feral cats has also been observed ( $T$. Minami, professional snake hunter, pers. comm.). In addition, rabbits were less abundant in the vicinity of cities and towns, where feral dogs and cats are more frequently observed, especially around both the city of Naze and the second largest township, Koniya (Fig. 3). Latrines were not observed in the west of region $\mathrm{A}$ where population density is high relative to the area west of Naze. These observations imply that predation may be an important factor in the decline of the rabbit on Amami Island. No information on predation is available for Tokuno Island.

Mosaics of young and mature forests are still abundant in the areas of relatively high population density in central Amami Island. Therefore, the primary conservation measure in such areas would be to limit forest road construction. This measure would restrict the logging of more mature forests and help prevent the isolation of some local populations.

Government subsidies that support the local economy are a key impediment to the conservation of the rabbit on Amami and Tokuno Islands. The government has 
provided financial support for the construction of forest roads, in order to assist local employment (Sugimura, 1988), as well as for the expansion of farmland. On Tokuno Island, where the two isolated populations may be critically endangered, large areas of forest have been replaced with farmland, so the current range is very small. If the rabbit's potential habitat is to be expanded, some farmland would need to be restored to forests. Furthermore, the nationally owned forests cover only about 10 per cent of the total forest lands on the two islands. Local municipalities, communities, private companies and individuals own the remainder, and they are more concerned with the economic benefits of forestry than with the conservation of rare species. Most of the forests on Amami and Tokuno Islands could be cut economically only when such forestry activities are supported by government subsidies (Sugimura, 1988).

A forest management policy that prevents the loss of mature forests and encourages the long-rotation management of the less mature forests (Harris, 1984) should be pursued to preserve the habitat of the Amami rabbit. Government finances previously directed towards destroying the habitat could be used to fund employment programmes that assist the conservation and long-term survival of one of Japan's wildlife treasures.

\section{Acknowledgements}

A number of people supported us in the completion of this research. Y. Abe, M. Igarashi, S. Yano, F. Maeda, H. Nagaoka and biology students from Kagoshima University assisted with the fieldwork. H. Kato and M. Ikejiri conducted laboratory works. I. Penna and S. Glushkoff proof-read the manuscript. We are also grateful to the Japanese Environment Agency, the Japan Wildlife Research Center and the World Wildlife Fund-Japan for financial support.

\section{References}

Anon. (1977) State of a Special Natural Monument, the Amami Rabbit: an Urgent Survey Report of a Natural Monument. Kagoshima-ken Board of Education, Kagoshima, Japan [in Japanese].

Chapman, J.A. \& Flux, J.E.C. (1990) Introduction and overview of the lagomorphs. In Rabbits, Hares and Pikas: Status Survey and Conservation Action Plan (eds J. A. Chapman and J. E. C. Flux), pp. 1-6. IUCN, Gland.

Duthie, A.G., Skinner, J.D. \& Robinson, T.J. (1989) The distribution and status of the riverine rabbit, Bunolagus monticularis, South Africa. Biological Conservation, 47, 195-202.

Fa, J.E. \& Bell, D.J. (1990) The volcano rabbit Romerolagus diazi. In Rabbits, Hares and Pikas: Status Survey and
Conservation Action Plan (eds J. A. Chapman and J. E. C. Flux), pp. 143-146. IUCN, Gland.

Fa, J.E., Romero, F.J. \& Lopez-Paniagua, D.J. (1992) Habitat use by parapatric rabbits in a Mexican high-altitude grassland system. Journal of Applied Ecology, 29, 357-370.

Glockling, S.L. \& Yamada, F. (1997) A survey of fungi which kill microscopic animals in the dung of the Amami rabbit. Mycologist, 11, 113-120.

Harris, L.D. (1984) The Fragmented Forest: Island Biogeography and the Preservation of Biotic Diversity. University of Chicago Press, Chicago.

Hoth, J., Valazquez, A., Romero, F.J., Leon, L., Aranda, M. \& Bell, D.J. (1987) The volcano rabbit-a shrinking distribution and a threatened habitat. Oryx, 21, 85-91.

Kagoshima-ken Amami Regional Office (1999) General Picture of the Amami Archipelago in 1998. Showa Printo, Kagoshima, Japan [in Japanese].

Kirino, M., Hayashi, Y. \& Suzuki, H. (1984) Food habits and activity patterns of the Amami rabbit Pentalagus furnessi. In Nansei Archipelago and its Nature Conservation (ed. WWF Japan Scientific Committee), pp. 303-307. WWF, Japan, Tokyo [in Japanese].

Ministry of Agriculture, Fishery and Forestry (1991) 1990 World Census of Agriculture and Forestry-Kagoshima Pref. (Forestry). Ministry of Agriculture, Fishery and Forestry, Statistics and Information Division, Tokyo [in Japanese].

Miyawaki, A., Inoue, K., Sasaki, Y., Fujiwara, K., Honda, M., Harada, H., Niiro, Y., Ohno, K., Ide, H., Suzuki, K. \& Ohno, H. (1974) Vegetation of Naze on Amami Island. Naze City Government, Naze, Japan [in Japanese].

Seber, G.A.F. (1982) The Estimation of Animal Abundance and Related Parameters. Charles Griffin \& Company, London.

Shimizu, Y., Yahara, T. \& Sugimura, K. (1988) Regeneration process after logging of the subtropical broad-leaved evergreen forest on Amami Oshima Island. Komazawa-chiri, 24, 31-56 [in Japanese with an English summary].

Sugimura, K. (1987) Forestry and wildlife conservation on Amami Oshima, Japan: an integrated study of wildlife and human society. PhD thesis, University of Hawaii at Manoa. Available from University Microfilms International, Ann Arbor.

Sugimura, K. (1988) The role of government subsidies in the population declines of some unique wildlife species on Amami Oshima, Japan. Environmental Conservation, 15, $49-57$.

Sugimura, K. (1993) On the ecology, distribution and population change of the Amami rabbit: an overview of the previous studies and some means of conservation. Chirimos, 4, 5-11 [in Japanese].

Sugimura, K. (1995) The effects of forest policy decisions on the fragmentation of mature forests and the habitat of rare wildlife species on Amami Oshima Island. Papers on Environmental Information Science, 9, 121-126 [in Japanese with an English summary].

Sugimura, K. (1998) The estimation of the population level of Amami rabbit (Pentalagus furnessi) and its declining trend. Papers on Environmental Information Science, 12, 251-256 [in Japanese with an English summary].

Tsukamoto, K. (1989) On the dung beetles in the Nansei Islands. Kyotofu Shigaku Kenkyu Ronshu, 27, 11-22 [in Japanese]. 
Velazquez, A. (1994) Distribution and population size of Romerolagus diazi on El Pelado Volcano, Mexico. Joumal of Mammalogy, 75, 743-749.

Velazquez, A. \& Heil, G.W. (1996) Habitat suitability study for the conservation of the volcano rabbit (Romerolagus diazi). Journal of Applied Ecology, 33, 543-554.

Wywialowski, A.P. \& Stoddart, L.C. (1988) Estimation of jack rabbit density: methodology makes a difference. Journal of Wildlife Management, 52, 57-59.

Yamada, F., Sugimura, K., Abe, S. \& Handa, Y. (2000) Present status and conservation of the endangered Amami rabbit Pentalagus furnessi. Tropics, 10, 89-94.

\section{Biographical sketches}

$\mathrm{K}$. Sugimura works as the head researcher at the Environmental Management Laboratory, National Institute of Forest Science, in Japan. His primary research interest is biodiversity conservation in the geographical context (integration of biological and social aspects). He has worked since 1984 on the conservation of endangered wildlife species on Amami and Tokuno Islands. He has also been involved in studies of forest evaluation for conservation planning and effects of global warming on forestry productivity since 1990 .

F. Yamada works as the head researcher at the Wildlife Ecology Laboratory, National Institute of Forest Science, in Japan. His primary research interest is ecology and management of lagomorphs. After studying ecology and management of the Japanese hare for 15 years, he started working on the Amami rabbit in 1992. Since then, he has been involved with both the conservation of the species and the ecology and control of the introduced mongoose, which has threatened the unique fauna of the island.

S. Sato works as a researcher at the Forest Protection Laboratory, Shikoku Research Center of the National Institute of Forest Science, in Japan. While his primary research interest is insect ecology and management, he has also been involved in ecology and conservation studies of avian communities. Since 1988, he has worked in the south-western part of Japan, including the Nansei Archipelago. He recently joined a research programme working on the River Shimanto, one of the most pristine riparian environments in Japan. 